Estevam Rodrigues de Castro, dadas a luz por Francisco de Castro, seu filho: Dirigidas ao illustríssimo senhor Capitão Pedro Capponi, cavaleiro do hábito de S. Estevão. Em Florenssa, por Zanobio Pinhoni, mercador de livros, 1623". Además, apareció en Florencia en 1639 una Postohuma varietas de las obras de Estevão Rodrigues, impresa por la misma casa (Amador Maffi y Lorenzo Landi) que más tarde publicó las Metamorfosis. Por eso parece fuera de duda que las Metamorfosis fueron obra de un Francisco de Castro, portugués, hijo de Estevão Rodrigues de Castro. Desgraciadamente, nada sabemos de su vida, fuera de lo que dice él mismo en la dedicatoria.

Sólo a título de curiosidad mencionaré otros dos personajes del mismo nombre que vivieron en el siglo xvir. Uno vivió de 1574 a 1653 y fue obispo de Guarda. Escribió una obra Augustissimo Hispaniarum principi recens nato Philippo Dominico Victorio Austriaco (Conimbricae, 16o6). El otro fue el segundo hijo del Conde de Lemos y lugarteniente de su padre en el reino de Nápoles de 1601 a 1603. En 1629 ingresó en la orden benedictina con el nombre de fray Agustín de Castro y murió en 1637. Bartolomé Leonardo de Argensola le dirigió el poema "Joven leal por el poder del hado..." $\mathrm{Ni}$ el uno ni el otro pudieron ser autor de las Metamorfosis.

KeNNETH R. Scholberg

Northwestern University.

\title{
EL DUENDE DE VALLADOLID DE GARCIA GUTIÉRREZ
}

En una nota al verso "Perdónenme mis lectores", al final del romance IV de su leyenda El duende de Valladolid ${ }^{1}$, Antonio García Gutiérrez hace saber que su fuente es el libro en castellano y latín del doctor Pedro Sánchez de Aguilar, Informe contra idolorum cultores del obispado de Yucatán ${ }^{2}$. El autor de El trovador llegó a conocer el pasaje del Informe que trata del estupendo duende de Valladolid durante su primera estancia en Mérida $^{3}$ y, necesariamente, por la intervención directa de don

${ }^{1}$ Poesias de Antonio Garcia Gutiérrez, sel. y pról. de J. de Entrambasaguas, Madrid, 1947 (Bibl. selecta de clás. españoles), pp. 357-377.

${ }^{2}$ Este volumen en $4^{\circ}$, con 8 folios prels. y 124 de texto, fue impreso por la viuda de Juan Gonçález, en Madrid, en 1639 . La $2^{\text {a }}$ ed. se publicó en México en 1892 en el t. 6, pp. 13-22, de los Anales del Museo Nacional, con la parte latina traducida por don Vicente de P. Andrade. La $3^{\text {a }}$ ed., que es la que utilizamos, va precedida de una breve biografía del autor por don Francisco Cantón Rosado, y fue impresa en 1937 en Mérida (Yucatán); se sirve de la reimpresión de 1892, de la cual toma sólo el texto en español.-Don Pedro Sánchez de Aguilar nació en Valladolid de México el 10 de abril de 1555 . Obtuvo el doctorado en la Universidad de México. Fue cura en varias parroquias antes de ascender a deán de la catedral de Mérida. El Rey de España le nombró canónigo de la catedral metropolitana de la ciudad de la Plata (hoy Sucre, Bolivia). Tomó posesión de su canonjía en 1621 , y continuó en el cargo hasta su muerte en 1648. Véase: "Duende de Valladolid", en Museo Yucateco, ed. Justo Sierra O'Reilly (periódico impreso en Campeche, año 1841), pp. 31b-32b; Gerónimo Castillo, Diccionario histórico, biográfico y monumental de Yucatán, Mérida, 1866, t. 1, pp. 282-284 (reproducción exacta de los comentarios de Sierra); Gustavo Martínez Alomía, Historiadores de Yucatán, Campeche, 1906, pp. 59-61; $3^{\text {a }}$ ed. del Informe, pp. i-iv y 197-203.

${ }^{3}$ Salió de la Habana el 18 de marzo de 1845 y antes del $1^{\circ}$ de abril ya estaba en 
Justo Sierra O'Reilly. Al parecer, por esos años no existía en Yucatán más que un ejemplar del raro Informe, el de don Justo ${ }^{4}$. Éste, sin duda, prestó su ejemplar al insigne visitante español y probablemente le dio a conocer la reproducción del relato sobre el duende que êl mismo había impreso cuatro años antes en el Museo Yucateco, núm. citado, pp. $29 b$ $3^{1} b^{5}$. Entusiasmado por el asunto, el dramaturgo español empezó a componer sus versos y pudo entregar algunos al Registro Yucateco, que ya los publicaba antes de su regreso a la Habana ${ }^{6}$. El Registro publicó el poema completo en los tomos 2 (pp. 33-34 y 71-73) y 3 (pp. 104-106, $380-382$ y $422-425)^{7}$.

Vale la pena señalar los datos concretos que toma García Gutiérrez del tosco pasaje de Sánchez de Aguilar sobre el duende de Valladolid (cf. la $3^{\text {a }}$ ed., pp. 114-118), puesto que así se puede apreciar mejor su relación con el poema. Esta leyenda en versos octosílabos, dividida en cinco romances y una conclusión, debe al Informe lo siguiente: el lugar de la acción, Valladolid de Yucatán; la fecha, 1570; el nombre de Álvaro Osorio, "hidalgo vezino" y, sin duda, persona de edad, puesto que es suegro de un conquistador, cuya casa frecuentaba el duende; algunos atributos del duende (tocaba la vihuela; hacía ruido en las casas; era mentiroso, testimoniero y cizañador); el cura Tomás Lersundi intentó conjurar al duende una noche por medio del ritual e hisopo que llevaba bajo la capa; vuelto el cura a su casa, encontró estiércol en la fuente, y la limeta llena de "un licor que... no lo digo"; reunidos los vecinos en cabildo para solicitar el favor del cielo, San Clemente Papa fue nombrado patrono de la villa; en el retablo de la iglesia, para conmemorar el milagro, se conserva una antigua pintura que muestra al santo con un demonio atado a sus pies.

Aprovechando estos pocos detalles, el poeta desarrolla la historia

Mérida, donde residió hasta el go de julio del mismo año, cuando partió para Cuba. Véase Diario de la Marina (La Habana), 19 de marzo de 1845 , p. 2; Siglo XIX (Mérida) t. 6 , núm. $5^{81}, 1^{\circ}$ de abril de 1845, p. 5 ; Registro Yucateco, Mérida, 1845 , t. 1 , p. 271 ; t. 2 , p. 114 .

4 Véase la $3^{\text {a }}$ ed. del Informe, p. 197. Y cf. José Antonio Cisneros, "Don Antonio García Gutiérrez", en Repertorio pintoresco, Mérida, 1863, pp. 204-205: "Nuestros inolvidables Sierra, Aznar y Calero obsequiaron al Trovador que había venido a eternizar en sus cantos algunas de nuestras ya casi olvidadas tradiciones populares".

5 Pero García Gutiérrez no aprovechó dicha reimpresión. En efecto, su composición sigue al pie de la letra el relato original y no cae en los ligeros errores que contiene la copia hecha por Justo Sierra: 1570 en lugar de 1560 , Serzundi en lugar de Lerzundi. Naturalmente, Gerónimo Castillo repite los mismos errores, puesto que su artículo es una copia de lo reproducido por Sierra. Véase Diccionario, pp. 279-282.

6 Véase Registro Yucateco, 1845, t. 2, p. 114 .

7 Otras ediciones: Mérida de Yucatán (Castillo y Compañía), 1846; Madrid (Imp. del Semanario e Ilustración, a cargo de D. G. Alhambra), $185^{\circ}$, 3o pp.; Madrid, en el Semanario Pintoresco Español, t. 15 (1850), 151-152 y 159-160; Poesías de Antonio Garcia Gutiérrez, ed. cit., pp. 357-377. Véase Ermilo Abreu Gómez y Paul Patrick Rogers, "Adiciones a la bibliografía de García Gutiérrez", HR, 2 (1934), 157-158; Poesias de ..., pp. xxxiv-xxxv. Martínez Alomía, op. cit., p. 152, se equivoca respecto al género literario de $E l$ duende de Valladolid al referirse a los estudios críticos de Gerónimo Castillo: "Entre sus obras literarias no debe omitirse la mención de... sus juicios críticos sobre los dramas $\mathrm{El}$ duende de Valladolid, La mujer valerosa y $\mathrm{El}$ secreto del ahorcado, que inspirándose en episodios de la historia de Yucatán, escribió el dramaturgo español don Antonio García Gutiérrez durante su permanencia en la Península..." 
de los amores del bizarro galán andaluz Francisco de Vargas, recién llegado a Valladolid de Yucatán, y de la hermosa Juanita, hija del anciano don Pedro Guzmán. El tirano padre ambiciona casarla con el rico don Alvaro Osorio, viejo "de cara torva, avinagrado carácter y catadura espantosa". Se da a entender que el valiente galán se finge duende, y que por ese medio espanta la villa y turba el sueño de todos. El cura trata en vano de poner fin a las travesuras del fantasma, con los resultados ya sabidos. Cesa por fin el diabólico trabajo del duende, tal vez por la eficaz intervención de San Clemente, aunque es curioso que eso suceda el mismo día en que don Pedro Guzmán consiente en las bodas de los amantes.

El tono del poema es puramente narrativo. El poeta versifica con corrección. Los detalles proporcionados por Sánchez de Aguilar se animan con la sencilla intriga amorosa, que a veces se convierte en parodia de las historias más serias y trágicas de otros muchos romances. La composición tiene gracia y humor. Por ejemplo, ridiculiza la credulidad y superstición, al mismo tiempo que pondera maliciosamente el valor del simple cura que se propone desterrar al duende (p. $3^{67}$ ):
¡Oh insigne varón! La historia,
en sus páginas de oro,
tu ilustre y preclaro nombre
hará a los siglos famoso.
¡Oh noble Tomás Lersundi, tan valiente como docto!
¡Tu memoria y remembranza
volarán de polo a polo!

Después de dos sorbos, "según unos de agua pura, / aunque hay quien diz si era mosto", el sacerdote recorre las calles oscuras, repitiendo un Pater noster tras otro y "bañando en agua bendita / puertas y guardacantones". No se aceptaría la descripción del desorden de los residuos de su cena a no atestiguarlo los códices. Hay tal disentimiento entre el clero sobre la elección de un santo patrono, que esto se deja a la suerte. Con el propósito de agregar elementos locales a su leyenda, el poeta emplea términos indios que define en notas: hace que el duende vierta la jicara del posole; precede a la comitiva nupcial la discordante música de instrumentos indígenas: stuches, sacatanes, tunkules, tortugas. En fin, El duende de Valladolid es una muestra excelente de los mejores romances de Antonio García Gutiérrez.

Indiana University.

Harvey L. Johnson 